\title{
The use of a simulation model as a game for teaching project control in construction
}

\author{
S.H. Al-Jibouri \\ University of Twente, Enschede, The Netherlands \\ s.h.al-jibouri@sms.utwente.nl \\ M.J. Mawdesley \\ School of Civil Engineering, University of Nottingham, UK \\ Michael.Mawdesley@nottingham.ac.uk
}

\begin{abstract}
Construction management education, like most education and indeed, most things, is changing rapidly. There is a move towards student centred learning which is intended to allow students to gain knowledge at their own pace and develop transferable skills during the course of their education.

In Construction Project control is an essential task of management of projects and good planning and control have long been recognised as having beneficial effects on the success of a project. However the efficacy of control techniques that are widely taught in management courses is almost impossible to prove. It is also very difficult on a theoretical basis to help students to understand the effects of their decisions and thereby enable them to learn the mixture of science and art, which is project control.

The use of management games for teaching in construction has the advantage of enabling participants to be put into complex, realistic project situations without incurring the financial and time penalties, which would accrue if real projects were used.

This paper describes a simulation model of an earthmoving project, which is used as a management game, to provide players with experience in the management and control of construction projects.

The model contains many of the aspects of a real project including planning, decision-making, uncertainty, environmental effects, finance and a realistic physical model of the project and resource operation. The paper draws conclusions both on its effectiveness for control and on its use for teaching and learning.
\end{abstract}

KEYWORDS: Construction; Management Games; Project Control, Simulation

\section{INTRODUCTION}

Project planning and control are two of the essential tasks of project management. Good planning and control have long been recognised as having beneficial effects on the success of a project. Poor planning and control, on the other hand, have also been recognised as major contributors to the poor performance of projects. Not surprisingly therefore, most, if not all, undergraduate courses in project management, contain elements of planning and control. Most medium and large sized organisations invest large amounts of money, time and effort, training their professionals in planning and control. Whilst this training is more practical than the theoretical approach adopted in most undergraduate programmes, the techniques used are usually traditional.

The effectiveness of the techniques taught in these courses is, at best, difficult to prove. Some work has been done to determine and illustrate the differences between different control mechanisms (see for example Al-Jibouri and Mawdesley, 1998) and several authors have developed new planning methods and criticised others (see for example Karim, 1999). However, such work is based on theories rather than practice and none of it takes into account all of the aspects of a project and the inherent complexity brought about by their interaction. 
In addition to the difficulty of assessing the effectiveness of planning and control, assessing the effectiveness and efficiency of a method of teaching them is problematical. People learn through a variety of mechanisms and what is viewed as good by one person for one topic may be viewed as being less good by another person or by the same person on a different topic. Some will like to learn by studying theories while others will like to learn by example and practice.
This paper describes an attempt to provide a mechanism for people to learn about planning and control of a project by experiencing them. It uses a simulation of a construction project which participants can plan and control with some degree of reality but without the inordinate cost implied by learning on a real project. The simulation model is described and experience with it is discussed. Student feedback on certain aspects is provided.

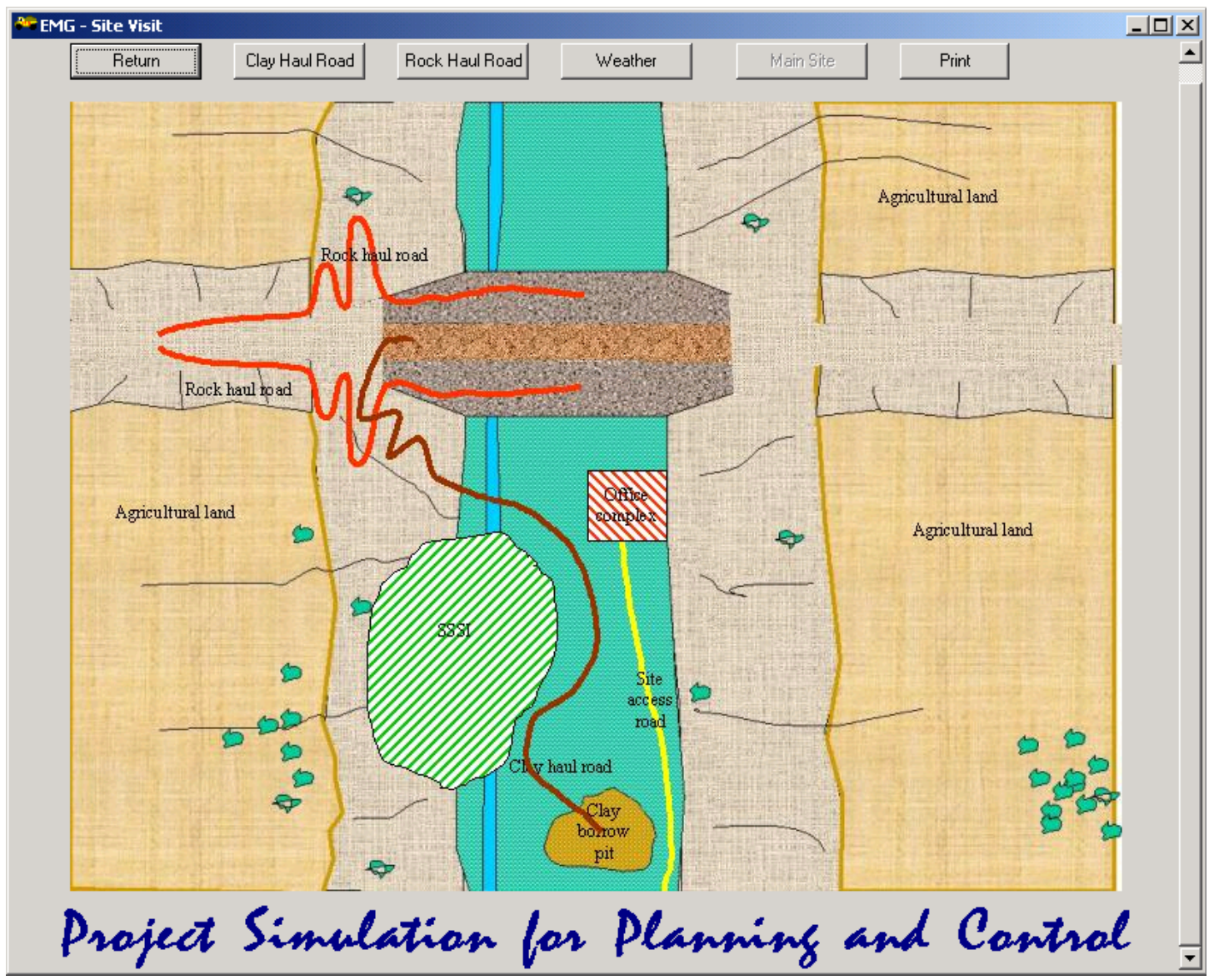

Figure 1. General arrangement of the site

\section{THE SIMULATION/ GAME}

The idea of using a computer simulation or management game to help students learn about complex issues is not new. Gilgeous and D'Cruz (1996) describe games stretching back over many years. The use of management games for teaching and learning about project planning and control is also not new and was described by Scott and Cullingford in 1973. Further, Au and Parti (1969) described the use of a game using a project with a significant amount of earthmoving as a basis. Not all games have to be complex and computer based and Tommelein et al (1999) describe one which can be run either manually or on a computer to illustrate the interaction of parties on a project. More recently, the Internet has featured with games as part of the learning environment (Sawhney et al 2001).

Despite all these developments, games are still little used in the real world, perhaps because of their inability to capture the attention of people brought up with computer games as a major form of entertainment.

Whilst not competing with the leisure games, this game combines the experience of players and traditional teachers and engineers to provide a user interface and style of play that is both interesting and informative. 
The detailed objectives of the game are:

- To provide a 'realistic' model of a construction project which will react in physical and financial terms to the decisions made and actions taken by the player

- To provide reports as might be expected on a real project
- To include uncertainty but to control it in such a manner as not to hide the effects of control actions

- To be suitable for use by both undergraduates and practicing engineers.

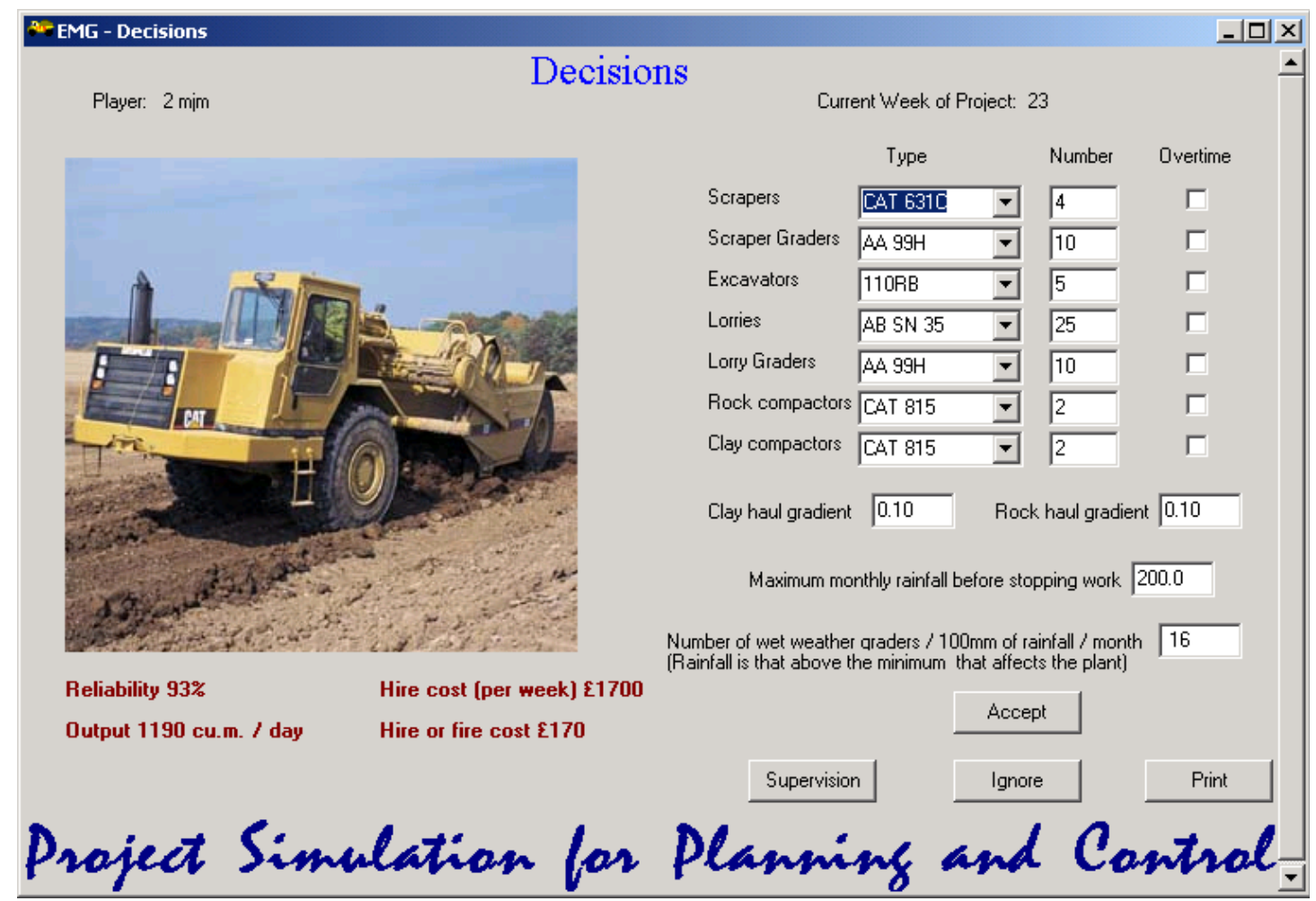

Figure 2. A typical decision screen

\subsection{The user interface}

The game is written in Pascal and was developed in the Borland Delphi IDE. The interface was designed to make use of the computer power and to develop and maintain the players' motivation and to present the players with reports which might be expected on a real project.

\subsection{The project}

The game is based on a project to construct a rock-fill dam with a clay core. The finished dam is $30 \mathrm{~m}$ high and $300 \mathrm{~m}$ wide at the top. Figure 1 shows a general arrangement of the site. It indicates some of the features to be considered by the player including the design and maintenance of temporary haul roads; the environmental impact of the work (including working close to a Site of Special Scientific Interest); and the effect of the work on neighbours. This is in addition to the normal planning and control considerations present on an isolated site.

\subsection{The player's tasks}

The player takes the part of the contractor's project manager and is responsible for the planning, resource selection and use, the control and the reporting to the company management.

Planning is required for both the physical and financial aspects of the project. It must be carried out and the project plan input to the computer before work can start on the actual construction. The plan can be amended at any time but the system remembers all plans and reports against the agreed one.

Resources are required to excavate, transport and place the rock and clay and to maintain the haul roads. A typical screen for the choice of plant is shown in Figure 2. Basic information on the 
equipment is provided on this screen but it is usually insufficient to make effective decisions. To aid the player and to increase the verisimilitude of the game various resources are provided. These include:

- Links to web sites of equipment companies such as Komatsu and Caterpillar

- Links to web sites of contracting organisations

- Links to notes and PowerPoint presentations on equipment selection and use

- Links to notes on the operation and use of teams of equipment.

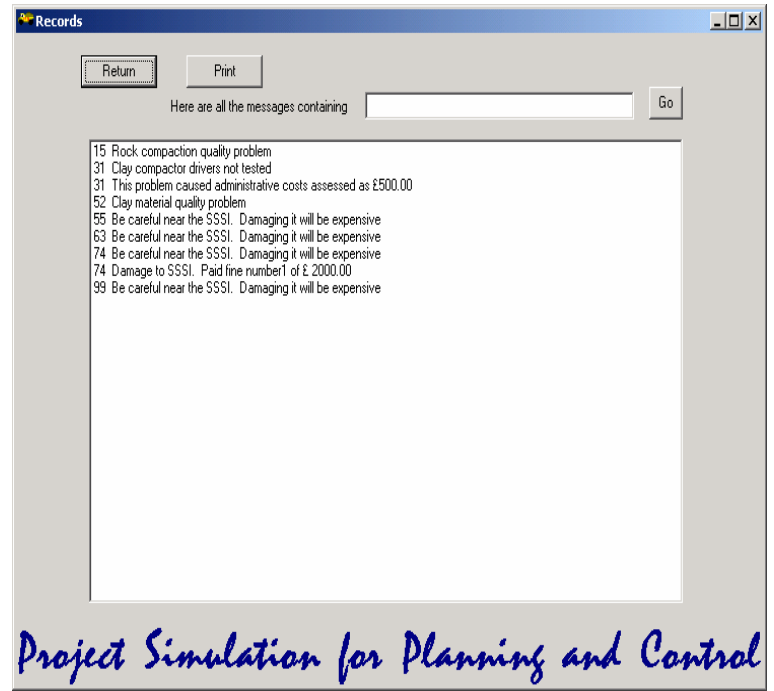

Figure 3. A typical text report screen

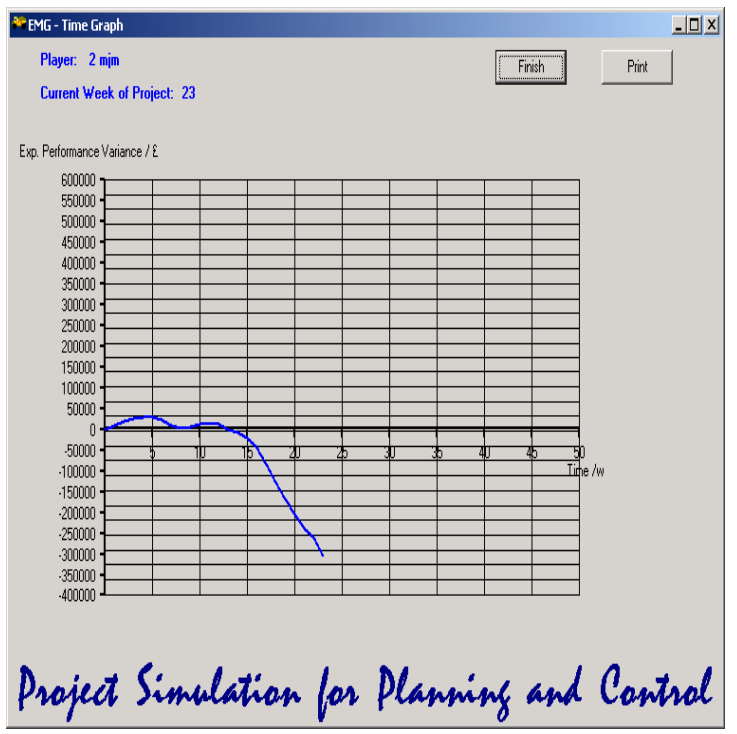

Figure 4. A typical variance graph
Management resources are also required and have to be selected by the player. For example, the number of engineers to supervise the rock excavation, transport and placing must be considered together with the amount of money to be spent on training them in the quality, safety and environmental matters.

\subsection{Reports}

The player receives reports from the game in many formats as would happen on a real project. There are some aspects which would be picked up from meetings and mail. These are reported as text and are illustrated in Figure 3. It can be seen that these refer to a large range of aspects including work quality, environmental impact, training issues and problems with progress. This type of information would be obtained from many sources in reality and would depend on the staff and reporting mechanisms on the project. In the game, the amount of this material also depends to some extent on the staff and its training.

The more formal control information can also be provided by the system although its availability depends directly on the staff employed. If few staff are employed, few reports will be produced or can be viewed. The information is available in numerical form or it be produced as several forms of graph. Figure 4 shows a graph of performance variance during construction.

All the most common control charts are available from the system and players can chose which they want to use to help them make decisions.

\section{EXPERIENCE WITH THE GAME}

The game has been run as part of a generally lecture based course. Participants worked in small groups (2,3 or 4$)$. Groups were both necessary, because of the large number in the class, and beneficial because they encouraged discussion and peer learning.

Before starting work on the project, each group was required to produce a programme of work, a financial plan and a proposed control method. These had to be presented to the main company board.

In every case, it was observed that the students were optimistic in their view of the project. The plans showed that the plant would work at optimum output, there would be no effect of team working, the plant fleets would always be balanced, no uncertain events would happen and control would hardly be necessary. Students were 
prepared to defend their view of the project even when questioned. They had analysed the data provided and were convinced that they had the 'correct' solution.

The agreed plan was input to the system before work on the dam commenced. Each group was then able to 'run the game' (or work on their own project) independently but had to report to the group board as agreed at the briefing.

The game monitored progress against this plan and attempted to make suggestions as to the need to re-plan. If re-planning were done, the system monitored against both the original plan and the most up-to-date plan available.

Participants very quickly realised the optimism of their original plan and took some form of control action. In almost all cases, this involved trying to build the plan at the planned rate and ignoring all other aspects (finance, quality, safety and the environment).

At the end of the project, each group was asked to report to the management board of the company to explain its performance. This ensured that the students thought carefully about their decisions.

Student feedback was also sought through a questionnaire. The main points reported by the students include:

- The difference between theory and practice

- The importance of obtaining realistic rather than optimistic data

- The importance of control

- The need for planning and control even when faced with an uncertain world

\section{EFFECTIVENESS OF CONTROL AND LEARNING}

The use of a game to teach management can be justified on many levels but it is important to attempt to assess its effectiveness. To this end, the game produces a summary measure of the performance of the player throughout the game and the results of this are presented below.

\subsection{The summary measure}

In addition to the normal project control parameters, the system produces a summary measure which is a linear arithmetic combination of the following factors:

- Current expenditure - planned expenditure

- Current income - planned income
- Current balance - planned balance

- Current clay height - planned clay height

- Current rock height - planned rock height The lower the value of the summary measure the better the player is performing relative to the plan. A score of 50 would be considered excellent and a score of 500 would be poor.

\subsection{Participant performance}

Eleven groups of 3 players were monitored during their playing of the game and the values of the summary measure, which they achieved, was recorded. The average result of the groups over time is shown in figure 5.

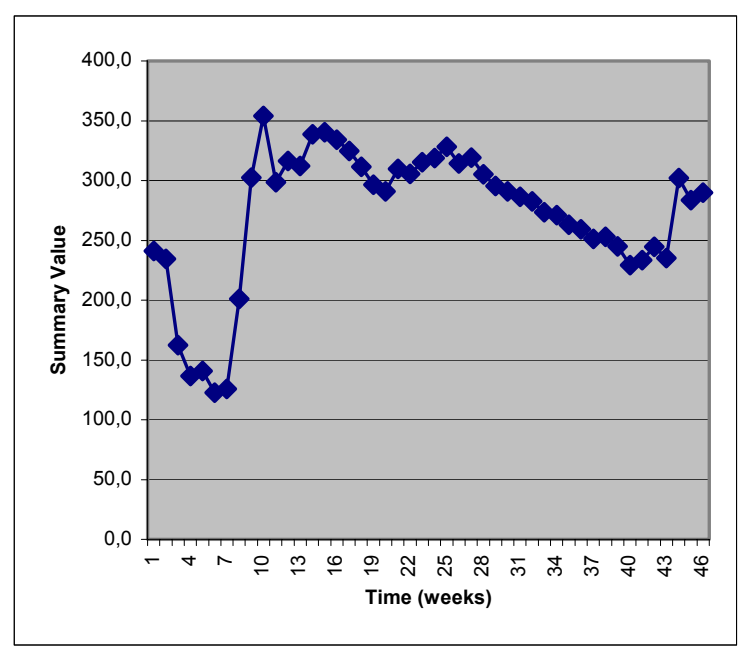

Figure 5. Average performance of groups

Several points can be made from these results.

Firstly, the game is made particularly easy at the start as the weather is set to have little uncertainty and consequently has a minimal effect on the progress of the work. This is reflected in the general reduction in the summary score over the first few weeks of the project. Players can use this initial period to understand the effects of control actions.

As the game progresses, the uncertainties inherent in the game increase. This is caused by many factors such as the equipment affecting the haul roads, the effects of the initial safety, quality and environmental training, and the weather changing as a different period of year is reached. At this stage, all players experienced a considerable amount of difficulty controlling their project to plan as can be seen by the marked increase in summary measure. 
However, players generally learned how to control the situation and the summary measure decreased in most cases. By the end of the project, the work could be considered to be in control although all were some considerable distance from their planned position. (The increase in measure towards the end of the project is caused by some groups going over their allowed duration and incurring liquidated damages costs)

Although this graph indicates a general improvement, the performance of the individual groups is not so clear. This is shown in figure 6 .

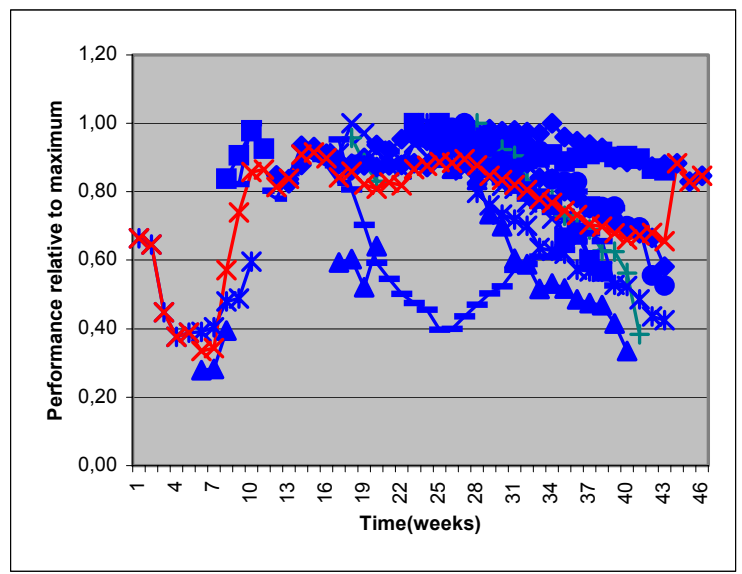

Figure 6. Performance of groups relative to their own worst measure value

In this figure, the performance of individual groups relative to their own maximum summary figure is shown. Once again, the smaller the value, the better the performance. From this it can be seen that some groups performed much better than others. The worst groups were still achieving summary measure values near their maximum $75 \%$ of the way through the project indicating that they were having great difficulty controlling their performance. This is also apparent in the shallow gradient of the line. The best groups, by contrast, were able to improve their performance consistently throughout the last half of the project.

\section{CONCLUSIONS}

The paper has described a game which has been produced to help with the teaching and learning of project planning and control. It has also described some of the experience gained from its operation. Students commented on how the game gave them and insight into the reality of projects, which theories did not allow.
The attempts at measuring the performance of the players provide some evidence of the learning effects of the game although more experiments are necessary to determine whether or not these are really achieved.

The game is based on a single dam-construction civil engineering project. Another game is under development based on the building industry and allowing players to experience the benefits and drawbacks of employing subcontractors rather than permanent employees.

\section{REFERENCES}

Al-Jibouri S. and Mawdesley M. J. (1998), Two cost control models and their effectiveness for controlling construction projects, Proceedings of the $\mathrm{XV}^{\text {th }}$ international cost engineering conference, Rotterdam, April.

Au T. and Parti E. (1969) Building Construction Game - General description, Journal of the Construction Division, ASCE, Vol. 95, No. CO1: $1-9$.

Gileous, V. and DÇruz, M., (1996) A study of business and management games, Management Development Review, Vol. 9 No. 1, pp.32-40.

Karim, A. and Adeli, H., (1999) "Object-Oriented Information Model for Construction Project Management", Journal of Construction Engineering and Management, ASCE, Vol. 125, Vol. 5, pp. 361-367.

Sawney A, Mund A and Koczenasz J (2001), Internet-Based Interactive Construction Management Learning System, Journal of Construction Education, Vol. 6, No. 3, 124-138

Scott D. and Cullingford G. (1973), Scheduling games for construction industry training, Journal of the Construction Division, Vol. 99, CO6: 81-92

Tommelein I., Riley D.R. and Howell G.A., (1999), Parade Game: Impact of Work Flow Variability on Trade Performance, Journal of Construction Engineering and Management, ASCE, $304-310$ 